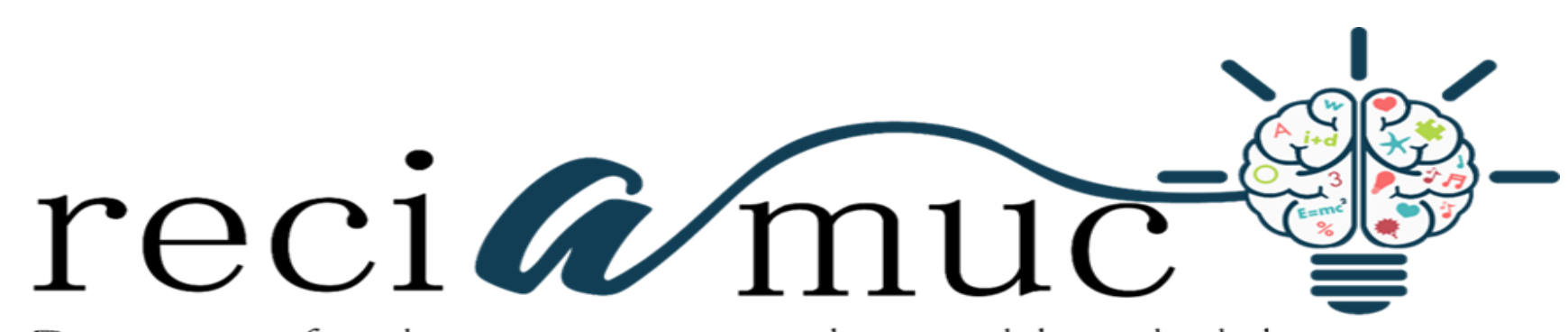

Revista científica de investigación actualización del mundo de las ciencias

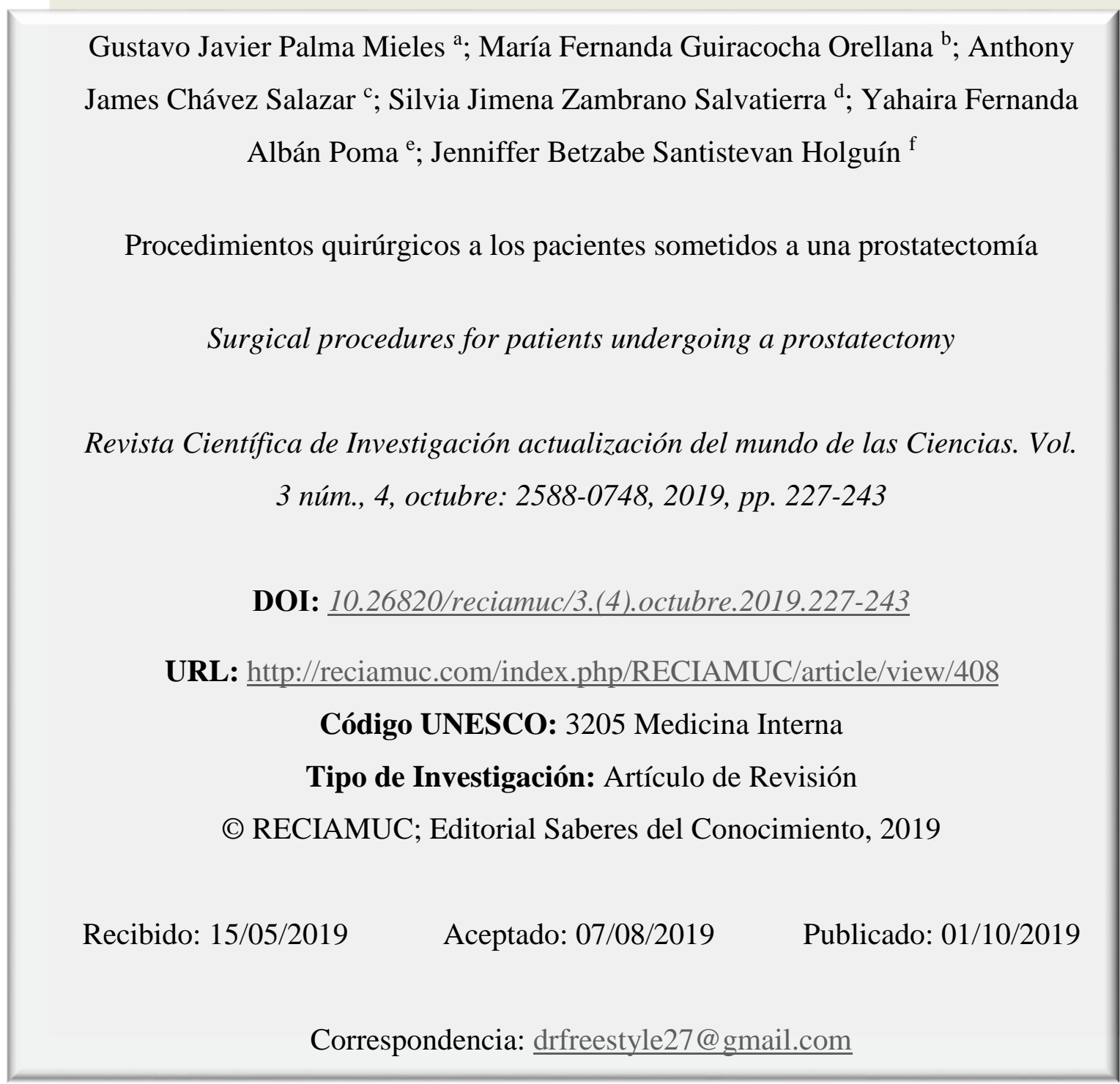

a. Médico Cirujano; Médico Atención Pre Hospitalaria - Hospital Jaime Roldos Aguilera; Los Ríos - Ecuador; drfreestyle27@gmail.com

b. Médica; Investigador Independiente; Cuenca - Ecuador; ferorellana1993@ hotmail.com

c. Doctor en Medicina; Médico Residente de Anestesia Hospital Marco Vinicio Iza; Lago Agrio - Ecuador; anthonyjames.med@gmail.com

d. Médica Cirujana; Médico residente del Hospital Básico San Andrés; Flavio Alfaro - Ecuador; silviajimena1993@gmail.com

e. Médico General; Médico residente del servicio de medicina interna - Hospital General Macas; Macas - Ecuador; yahyfer@hotmail.com

f. Médico Cirujano; Médico General en funciones hospitalarias - Hospital Básico Jipijapa; Jipijapa - Ecuador; jebesanhol@hotmail.com 


\section{Procedimientos quirúrgicos a los pacientes sometidos a una prostatectomía}

Vol. 3, núm. 4., (2019)

Gustavo Javier Palma Mieles; María Fernanda Guiracocha Orellana; Anthony James Chávez Salazar; Silvia Jimena Zambrano Salvatierra; Yahaira Fernanda Albán Poma; Jenniffer Betzabe Santistevan Holguín

\section{RESUMEN}

El cáncer de próstata es una enfermedad en la que se desarrollan células malignas (cancerosas) en los tejidos de la próstata. Es posible que los pacientes con buen estado de salud y un tumor que solo está en la glándula prostática se traten con cirugía para extirpar el tumor. Se utilizan los siguientes tipos cirugía: prostatectomía radical: procedimiento quirúrgico para extirpar la próstata, el tejido circundante y las vesículas seminales, prostatectomía retropúbica: procedimiento quirúrgico para extirpar la próstata a través de una incisión (corte) en la pared abdominal. El cirujano hace una incisión en la parte baja del abdomen, desde el ombligo hasta el hueso púbico, prostatectomía perineal: procedimiento quirúrgico para extirpar la próstata a través de una incisión (corte) en el perineo (área entre el escroto y el ano), linfadenectomía pélvica: cirugía para extirpar los ganglios linfáticos de la pelvis. Un patólogo observa el tejido al microscopio para verificar si hay células cancerosas. Si los ganglios linfáticos tienen cáncer, el médico no extirpará la próstata y es posible que se sugiera otro tratamiento, la resección transuretral de la próstata (RTUP): procedimiento quirúrgico para extirpar tejido de la próstata mediante un resectoscopio (un tubo delgado con iluminación y un instrumento cortante) que se inserta a través de la uretra. Este procedimiento se realiza para tratar la hipertrofia prostática benigna, para aliviar los síntomas que causan un tumor antes de administrar otro tratamiento del cáncer. En una prostatectomía radical laparoscópica el cirujano hace varias incisiones pequeñas, a través de las cuales se insertan instrumentos especiales y largos para extirpar la próstata. Uno de los instrumentos tiene una pequeña cámara de video en el extremo que permite al cirujano observar dentro del abdomen. El sistema robótico puede proveer más maniobrabilidad y más precisión cuando se mueven los instrumentos que con la prostatectomía radical laparoscópica convencional. Los posibles efectos secundarios principales de la prostatectomía radical son la incontinencia urinaria y la disfunción eréctil. La metodología usada es descriptiva, con un enfoque documental, es decir, revisar fuentes disponibles en la red, como google académico, con contenido oportuno y relevante desde el punto de vista científico y actualizado que enriquezca el análisis del tema planteado en este artículo.

Palabras Claves: Tumor; Cáncer; Prostatectomía Radical; Prostatectomía Retropúbica; Prostatectomía Laparoscópica; Robótica; Incontinencia. 


\section{Procedimientos quirúrgicos a los pacientes sometidos a una prostatectomía}

Vol. 3, núm. 4., (2019)

Gustavo Javier Palma Mieles; María Fernanda Guiracocha Orellana; Anthony James Chávez

Salazar; Silvia Jimena Zambrano Salvatierra; Yahaira Fernanda Albán Poma; Jenniffer Betzabe

Santistevan Holguín

\section{ABSTRACT}

Prostate cancer is a disease in which malignant (cancer) cells develop in the tissues of the prostate. Patients with good health and a tumor that is only in the prostate gland may be treated with surgery to remove the tumor. The following types of surgery are used: radical prostatectomy: surgical procedure to remove the prostate, surrounding tissue and seminal vesicles, retropubic prostatectomy: surgical procedure to remove the prostate through an incision (cut) in the abdominal wall. The surgeon makes an incision in the lower abdomen, from the navel to the pubic bone, perineal prostatectomy: surgical procedure to remove the prostate through an incision (cut) in the perineum (area between the scrotum and anus), pelvic lymphadenectomy: surgery to remove lymph nodes from the pelvis. A pathologist looks at the tissue under a microscope to check for cancer cells. If the lymph nodes have cancer, the doctor will not remove the prostate and another treatment, transurethral resection of the prostate (TURP) may be suggested: surgical procedure to remove prostate tissue using a resectoscope (a thin tube with illumination and a cutting instrument) that is inserted through the urethra. This procedure is done to treat benign prostatic hypertrophy, to relieve the symptoms that cause a tumor before administering another cancer treatment. In a laparoscopic radical prostatectomy, the surgeon makes several small incisions, through which special and long instruments are inserted to remove the prostate. One of the instruments has a small video camera at the end that allows the surgeon to observe inside the abdomen. The robotic system can provide more maneuverability and more precision when instruments are moved than with conventional laparoscopic radical prostatectomy. The possible main side effects of radical prostatectomy are urinary incontinence and erectile dysfunction. The methodology used is descriptive, with a documentary approach that is, reviewing sources available on the web, such as google scholar, with timely and relevant content from the scientific and updated point of view that enriches the analysis of the topic raised in this article.

Key Words: Tumor; Cancer; Radical prostatectomy; Retropubic prostatectomy; Laparoscopic prostatectomy; Robotics; Incontinence. 


\section{Procedimientos quirúrgicos a los pacientes sometidos a una prostatectomía}

Vol. 3, núm. 4., (2019)

Gustavo Javier Palma Mieles; María Fernanda Guiracocha Orellana; Anthony James Chávez Salazar; Silvia Jimena Zambrano Salvatierra; Yahaira Fernanda Albán Poma; Jenniffer Betzabe Santistevan Holguín

\section{Introducción.}

Los avances en la comprensión de la anatomía de la próstata en los años recientes han significado una contribución sustancial para mejorar la técnica quirúrgica en el tratamiento del cáncer de próstata, con la preservación potencial de las estructuras anatómicas responsables de las funciones eréctil y urinaria post operatoria. El conocimiento de estas estructuras anatómicas es el punto central para conseguir una extirpación completa de la próstata y las vesículas seminales, preservando a la vez la mejor calidad de vida posible.

Este tipo de cáncer está relacionado con la edad del paciente, a mayor edad mayor posibilidad de enfermedad. Es importante de un buen examen físico, de imagen, laboratorio, PCA total, previo a la derivación de especialidad. El tacto rectal está indicado en las guías de práctica clínica y, por lo tanto, hay que recomendarlo a los pacientes como medida preventiva a partir de los 40 años, si reporta factores de riesgo.

Si tiene alguno de estos síntomas es conveniente acudir al especialista: problemas al orinar, incluyendo un flujo urinario lento o debilitado o necesidad de orinar con más frecuencia, especialmente de noche, sangre en la orina o el semen, disfunción eréctil, dolor en las caderas, la espalda (columna vertebral), el tórax (costillas) u otras áreas debido a que el cáncer que se ha propagado a los huesos, debilidad o adormecimiento de las piernas o los pies, o incluso pérdida del control de la vejiga o los intestinos debido a que el cáncer comprime la médula espinal. Es más probable que la mayoría de estos problemas sean por causa distinta al cáncer de próstata, Aun así, resulta importante que usted le informe a su médico si presenta cualquiera de estos síntomas para que la causa se encuentre y se trate, de ser necesario.

La cirugía es una opción común para tratar de curar el cáncer de próstata siempre que no se halla propagado hacia el exterior de la glándula prostática. El principal tratamiento quirúrgico para el cáncer de próstata es la prostatectomía radical. En este procedimiento el cirujano extirpa toda la glándula prostática además de una porción del tejido que lo rodea, incluyendo las vesículas seminales. Existen diferentes técnicas para realizar la prostatectomía radical que serán abordadas en la presentación de resultados de este artículo. 


\section{Procedimientos quirúrgicos a los pacientes sometidos a una prostatectomía}

Vol. 3, núm. 4., (2019)

Gustavo Javier Palma Mieles; María Fernanda Guiracocha Orellana; Anthony James Chávez

Salazar; Silvia Jimena Zambrano Salvatierra; Yahaira Fernanda Albán Poma; Jenniffer Betzabe

Santistevan Holguín

\section{Metodología.}

Esta investigación está dirigida al estudio del "Procedimientos quirúrgicos a los pacientes sometidos a una prostatectomía.". Para realizarlo se usó una metodología tipo descriptiva, con un enfoque documental, es decir, revisar fuentes disponibles en la red, como google académico, con contenido oportuno y relevante desde el punto de vista científico para dar respuesta a lo tratado en el presente artículo y que sirvan de inspiración para realizar otros proyectos. Las mismas pueden ser consultadas al final, en la bibliografía.

\section{Resultados.}

El cáncer de próstata es una enfermedad en la que se desarrollan células malignas (cancerosas) en los tejidos de la próstata. La próstata es una glándula del aparato reproductor masculino que queda justo debajo de la vejiga (el órgano que recoge y desecha la orina) y delante del recto (la parte inferior del intestino). Su tamaño es como el de una nuez y rodea una parte de la uretra (el tubo que conduce la orina al exterior desde la vejiga). La glándula prostática elabora un líquido que es parte del semen. Es posible que los pacientes con buen estado de salud y un tumor que solo está en la glándula prostática se traten con cirugía para extirpar el tumor. Se utilizan los siguientes tipos cirugía (Instituto Nacional del Cáncer, 2017):

Prostatectomía radical: procedimiento quirúrgico para extirpar la próstata, el tejido circundante y las vesículas seminales. También definido como métodos abiertos de prostatectomía radical. Hay dos tipos de prostatectomía radical:

- Prostatectomía retropúbica: procedimiento quirúrgico para extirpar la próstata a través de una incisión (corte) en la pared abdominal. El cirujano hace una incisión en la parte baja del abdomen, desde el ombligo hasta el hueso púbico. Simultáneamente se pueden extirpar los ganglios linfáticos cercanos, los ganglios se envían a un laboratorio de patología para ver si tienen células cancerosas, en algunos casos los ganglios se pueden examinar durante la cirugía. se encuentran células cancerosas en cualquiera de los ganglios linfáticos, puede que el cirujano suspenda la cirugía. Esto se debe a que es poco 


\section{Procedimientos quirúrgicos a los pacientes sometidos a una prostatectomía}

Vol. 3, núm. 4., (2019)

Gustavo Javier Palma Mieles; María Fernanda Guiracocha Orellana; Anthony James Chávez Salazar; Silvia Jimena Zambrano Salvatierra; Yahaira Fernanda Albán Poma; Jenniffer Betzabe Santistevan Holguín

probable que el cáncer sea curado mediante cirugía, y a que extirpar la próstata podría ocasionar graves efectos secundarios. (Secin, 2010).

- Prostatectomía perineal: procedimiento quirúrgico para extirpar la próstata a través de una incisión (corte) en el perineo (área entre el escroto y el ano). Los ganglios linfáticos también se pueden extirpar a través de otra incisión en el abdomen. Este método se usa con menos frecuencia debido a que es más probable que dé lugar a problemas con erecciones y porque no se pueden extirpar los ganglios linfáticos. Es una operación más breve y puede ser una opción si no se requiere extirpar los ganglios linfáticos. La operación perineal usualmente requiere menos tiempo que la operación retropúbica, y puede causar menos dolor, y posteriormente una recuperación más fácil (American Cancer Society, 2017).

Pueden presentarse otras complicaciones directamente en relación con la operación de prostatectomía radical ( Sociedad Chilena de Urología, 2018):

$\checkmark$ Riesgo vital excepcional por hemorragia.

$\checkmark$ Complicaciones durante la intervención y complicaciones posoperatorias precoces.

$\checkmark$ Hemorragia que pudiera requerir una transfusión sanguínea.

$\checkmark$ Lesión del uréter que pudiera requerir una reparación.

$\checkmark$ Perforación del recto debido a su proximidad a la próstata y al tumor.

$\checkmark$ Infección urinaria que requiera tratamiento antibiótico.

$\checkmark$ Hematoma, usualmente a nivel de la herida operatoria.

$\checkmark$ Cura mediante drenaje local y excepcionalmente obliga a un re intervención.

$\checkmark$ Fuga de orina a través del drenaje que se corrige generalmente manteniendo el drenaje por un tiempo prolongado y conservando la sonda urinaria.

$\checkmark$ Derrame de linfa o colección pelviana (linfocele): en caso de disección ganglionar; rara vez requiere un re intervención quirúrgica.

$\checkmark$ Incontinencia urinaria.

$\checkmark$ Pérdida de la erección aumenta con la edad y con el tamaño del tumor. 


\section{Procedimientos quirúrgicos a los pacientes sometidos a una prostatectomía}

Vol. 3, núm. 4., (2019)

Gustavo Javier Palma Mieles; María Fernanda Guiracocha Orellana; Anthony James Chávez

Salazar; Silvia Jimena Zambrano Salvatierra; Yahaira Fernanda Albán Poma; Jenniffer Betzabe

Santistevan Holguín

\section{$\checkmark$ Estrechez uretral.}

$\checkmark$ Hernia de la pared abdominal: puede ser necesaria una reparación quirúrgica.

- Linfadenectomía pélvica: cirugía para extirpar los ganglios linfáticos de la pelvis. Un patólogo observa el tejido al microscopio para verificar si hay células cancerosas. Si los ganglios linfáticos tienen cáncer, el médico no extirpará la próstata y es posible que recomiende otro tratamiento.

- Resección transuretral de la próstata (RTUP): procedimiento quirúrgico para extirpar tejido de la próstata mediante un resectoscopio (un tubo delgado con iluminación y un instrumento cortante) que se inserta a través de la uretra. Este procedimiento se realiza para tratar la hipertrofia prostática benigna y, a veces, para aliviar los síntomas que causan un tumor antes de administrar otro tratamiento del cáncer. La RTUP también se realiza en hombres cuyo tumor está solo en la próstata y a quienes no se les puede practicar una prostatectomía radical.

Las indicaciones de la RTUPC incluyen a aquellos pacientes con cáncer de próstata localizado comprobado histológicamente, estadios T1-2 y T3 a determinados con estadiaje preoperatorio mediante examen dígito rectal (EDR), ecografía transrectal, antígeno prostático específico (PSA), gammagrafía ósea, tomografía computarizada y radiología pulmonar. La enfermedad metastásica incluyen aquellos pacientes que no son subsidiarios o que rechazan la cirugía abierta (Reuter, 2008).

\section{Métodos laparoscópicos para prostatectomía radical.}

Los métodos laparoscópicos conllevan realizar varias incisiones más pequeñas, se usan instrumentos quirúrgicos especiales y largos para extraer la próstata. El cirujano sostiene directamente los instrumentos, o usa un panel de control para mover con precisión los brazos robóticos que sostienen los instrumentos. Este modo de realizar la prostatectomía se ha vuelto más frecuente en los últimos años. 


\section{Procedimientos quirúrgicos a los pacientes sometidos a una prostatectomía}

Vol. 3, núm. 4., (2019)

Gustavo Javier Palma Mieles; María Fernanda Guiracocha Orellana; Anthony James Chávez Salazar; Silvia Jimena Zambrano Salvatierra; Yahaira Fernanda Albán Poma; Jenniffer Betzabe Santistevan Holguín

\section{Prostatectomía radical laparoscópica.}

En una prostatectomía radical laparoscópica (laparoscopic radical prostatectomy, LRP), el cirujano hace varias incisiones pequeñas, a través de las cuales se insertan instrumentos especiales y largos para extirpar la próstata. Uno de los instrumentos tiene una pequeña cámara de video en el extremo que permite al cirujano observar dentro del abdomen.

La prostatectomía laparoscópica tiene sus ventajas sobre la prostatectomía radical abierta, incluyendo menos pérdida de sangre y dolor, estadías más breves en el hospital (usualmente no más de un día) y períodos de recuperación más cortos (aunque será necesario mantener el catéter en la vejiga por aproximadamente la misma cantidad de tiempo). Cuando se realiza por médicos con experiencia en el procedimiento, la prostatectomía radical laparoscópica parece ser tan eficaz como la prostatectomía radical abierta (Arroyo, 2007).

Las tasas de los principales efectos secundarios de la LRP, tales como problemas de erección y dificultad para retener la orina (incontinencia) parecen ser casi las mismas que para la prostatectomía abierta.

Las indicaciones de la prostatectomía radical laparoscópica son adenocarcinoma de próstata localizado (T1-T2) sin metástasis en pacientes con una esperanza de vida superior a 10 años y el localmente avanzado (T3) sin metástasis con una esperanza de vida superior a 10 años e informando a los pacientes que es probable que precise complementar el tratamiento con radioterapia. Para poder realizar la prostatectomía radical laparoscópica es conveniente que el paciente no haya sufrido ninguna cirugía abdominal previa.

El procedimiento está indicado en el carcinoma prostático en varones de hasta 70 o 75 años. El tipo del tumor va a influir en la decisión terapéutica de realizar una prostatectomía radical laparoscópica. Hay que considerar el estado de salud del paciente, la esperanza de vida (normalmente no inferior a 10 años), la supervivencia libre de enfermedad calculada con nomogramas, la calidad de vida actual y las expectativas posteriores y las complicaciones de este 


\section{Procedimientos quirúrgicos a los pacientes sometidos a una prostatectomía}

Vol. 3, núm. 4., (2019)

Gustavo Javier Palma Mieles; María Fernanda Guiracocha Orellana; Anthony James Chávez Salazar; Silvia Jimena Zambrano Salvatierra; Yahaira Fernanda Albán Poma; Jenniffer Betzabe

Santistevan Holguín

tratamiento, como impotencia e incontinencia urinaria de esfuerzo, entre otros, pueden influir determinantemente en la elección de este tratamiento (El Médico Interactivo, 2017).

Son varias las ventajas potenciales de la prostatectomía radical laparoscópica extraperitoneal frente a la prostatectomía radical laparoscópica por vía transperitoneal (Castillo, 2006):

- Se evitan las complicaciones derivadas de la disminución del retorno venoso propias del neumoperitoneo.

- Se facilita el acceso en pacientes con cirugías intra-abdominales previas al evitar las sinequias y adherencias intraperitoneales; el mantener el campo quirúrgico fuera de la cavidad peritoneal, minimiza la posibilidad de complicaciones mecánicas o térmicas sobre las vísceras huecas intra abdominales.

- Tiene la facultad de confinar potenciales complicaciones como sangrado y filtración urinaria al espacio extraperitoneal, brindando la posibilidad de un tratamiento conservador en estos casos.

Una dificultad que presenta la técnica extraperitoneal es la creación de una adecuada cámara de trabajo, (debido a que ésta se debe realizar en un espacio virtual). Existen diferentes métodos y técnicas desarrolladas para la creación de este espacio de trabajo, que van desde la disección digital roma del espacio de Retzius, hasta la utilización de dispositivos de balón ofrecidos en el mercado. El uso de un balón se elabora con el dedo medio de un guante quirúrgico, anudado sobre el extremo de una sonda de nelaton. Este instrumento permite el desarrollo de un adecuado espacio de trabajo, con una técnica sencilla, reproducible, a muy bajo costo.

La excelente visualización del campo operatorio y la óptica, permiten la realización de una anastomosis vesicouretral detallada e impermeable, disminuyendo el tiempo de cateterización postoperatoria. Estas mismas la cirugía laparoscópica, facilita la realización de la anastomosis vesicouretral de diversas formas: con puntos separados, mediante sutura continua, o combinando ambas técnicas. 


\section{Procedimientos quirúrgicos a los pacientes sometidos a una prostatectomía}

Vol. 3, núm. 4., (2019)

Gustavo Javier Palma Mieles; María Fernanda Guiracocha Orellana; Anthony James Chávez Salazar; Silvia Jimena Zambrano Salvatierra; Yahaira Fernanda Albán Poma; Jenniffer Betzabe Santistevan Holguín

\section{Prostatectomía radical laparoscópica asistida por robot.}

En este método, conocido también como prostatectomía robótica, la cirugía laparoscópica se hace mediante el uso de un sistema robótico. El cirujano se sienta frente a un panel de control cercano a la mesa de operaciones y mueve los brazos robóticos para operar a través de varias incisiones pequeñas que se hacen en el abdomen del paciente. Ofrece ventajas sobre el método abierto en términos de menos dolor, pérdida de sangre y tiempo de recuperación. Sin embargo, en términos de los efectos secundarios: problemas urinarios o problemas de erección, parece no haber una diferencia entre la prostatectomía robótica y otros métodos.

Para el cirujano, el sistema robótico puede proveer más maniobrabilidad y más precisión cuando se mueven los instrumentos que con la prostatectomía radical laparoscópica convencional. Aun así, la experiencia y la destreza del cirujano son los factores más importantes en el éxito de cualquiera de los dos tipos de cirugía laparoscópica.

\section{Prostatectomía con robot da Vinci.}

La Cirugía da Vinci para el cáncer de próstata incorpora las mejores técnicas de la cirugía tradicional, es un método mínimamente invasivo, asistido por robot. En una prostatectomía radical, laparoscópica asistida por robot el cirujano realiza varios orificios pequeños $(0,5-1 \mathrm{~cm})$ en la piel, a través de los cuales inserta instrumentos especiales para extirpar la próstata que moverá desde el exterior guiándose por un sistema de visualización estereoscópica de alta definición. La cámara de video en el extremo permite que el cirujano pueda observar dentro del abdomen, logrando una mayor precisión y manejo más delicado de las estructuras vitales. También se introduce gas (CO2) para favorecer la visión del interior del abdomen creando un espacio amplio para desarrollar la cirugía (Gómez, 2018).

\section{Beneficios de la intervención con da Vinci (Gárate, 2017):}

- Estancia hospitalaria más corta.

- Menos pérdida de sangre. 


\section{Procedimientos quirúrgicos a los pacientes sometidos a una prostatectomía}

Vol. 3, núm. 4., (2019)

Gustavo Javier Palma Mieles; María Fernanda Guiracocha Orellana; Anthony James Chávez Salazar; Silvia Jimena Zambrano Salvatierra; Yahaira Fernanda Albán Poma; Jenniffer Betzabe

Santistevan Holguín

- Menor necesidad de transfusiones de sangre.

- Menor riesgo de complicaciones.

- Menor riesgo de infección de heridas.

- Menos días con catéter.

- Menos dolor.

- Recuperación más rápida y vuelta a las actividades normales en un periodo de tiempo menor.

- Retorno más rápido de la función eréctil (sexual).

- Mayores probabilidades de recuperación de la continencia urinaria.

El sistema robótico ofrece al cirujano mejor maniobrabilidad y precisión que la que tenía durante la cirugía abierta o la cirugía laparoscópica convencional:

- El tejido que rodea la fascia endopélvica puede ser identificado, delineado, y expuesto fácilmente utilizando sistema de visión 3D HD y los instrumentos Endo Wrist totalmente articulados

- Aumento de la retracción y del control sobre la uretra posterior para ayudar en la sección del cuello de la vejiga

- La disección cuidadosa del ápex prostático permite preservar toda la longitud de la uretra

- Preservación delos nervios erectores y disección precisa de la próstata

- Colocación de la aguja de sutura precisa y necesaria para realizar una anastomosis entre vejiga y uretra.

Efectos secundarios de la cirugía de próstata 


\section{Procedimientos quirúrgicos a los pacientes sometidos a una prostatectomía}

Vol. 3, núm. 4., (2019)

Gustavo Javier Palma Mieles; María Fernanda Guiracocha Orellana; Anthony James Chávez Salazar; Silvia Jimena Zambrano Salvatierra; Yahaira Fernanda Albán Poma; Jenniffer Betzabe Santistevan Holguín

Los posibles efectos secundarios principales de la prostatectomía radical son la incontinencia urinaria y la disfunción eréctil. Estos efectos secundarios también pueden manifestarse con otras formas de tratamiento para el cáncer de próstata (Eisenberg, 2016).

Incontinencia urinaria: dificultad para controlar la orina o presente fuga o goteo de orina. Hay diferentes niveles de incontinencia. Los siguientes son los tres tipos principales de incontinencia. Los hombres con incontinencia urinaria de esfuerzo podrían perder orina cuando tosen, se ríen, estornudan o hacen ejercicio. Por lo general, los problemas con la válvula que retiene la orina en la vejiga (esfínter de la vejiga) causa la incontinencia de esfuerzo. Los hombres que padecen incontinencia por rebosamiento presentan dificultad para vaciar la vejiga. Estos hombres se tardan mucho en orinar y tienen un flujo goteante con poca fuerza. Los hombres que padecen incontinencia de urgencia tienen una necesidad repentina de orinar. Este problema ocurre cuando la vejiga se vuelve demasiado sensible al estiramiento conforme se llena de orina.

Disfunción eréctil (impotencia): esto significa que no se puede lograr una erección suficiente para la penetración sexual. Después de esta operación, la capacidad de lograr erecciones depende de la edad, la capacidad que tenía usted de lograr erecciones antes de la operación, y si se cortaron los nervios. Todos los hombres pueden esperar una reducción en la capacidad de tener erecciones, pero cuanto más joven usted sea, hay más probabilidades de que conserve esta capacidad.

Cambios en el orgasmo: posterior a la cirugía, la sensación del orgasmo debe continuar siendo placentera, pero no hay eyaculación de semen (el orgasmo es seco). Esto se debe a que las glándulas que producen la mayor parte del líquido para el semen (las vesículas seminales y la próstata) fueron extirpadas durante la prostatectomía, y las vías por las que pasaba el esperma (el conducto deferente) fueron cortadas. En algunos hombres, los orgasmos pueden ser de menor intensidad o desaparecer por completo.

Infertilidad: la prostatectomía radical corta los conductos deferentes, los tubos que se encuentran entre los testículos (donde se produce el esperma) y la uretra (por donde el esperma sale del cuerpo). Sus testículos seguirán produciendo esperma, aunque éste no podrá salir del cuerpo como parte de la eyaculación. 


\section{Procedimientos quirúrgicos a los pacientes sometidos a una prostatectomía}

Vol. 3, núm. 4., (2019)

Gustavo Javier Palma Mieles; María Fernanda Guiracocha Orellana; Anthony James Chávez

Salazar; Silvia Jimena Zambrano Salvatierra; Yahaira Fernanda Albán Poma; Jenniffer Betzabe

Santistevan Holguín

Linfedema: es una complicación poco común, puede presentar después de la extirpación de muchos de los ganglios linfáticos alrededor de la próstata. Normalmente los ganglios linfáticos son una vía para el retorno de líquido hacia el corazón desde todas las áreas del cuerpo. Cuando se extirpan los ganglios, se puede acumular líquido en las piernas o en la región genital con el pasar del tiempo, lo que causa hinchazón y dolor.

Cambio en la longitud del pene: puede ocurrir una pequeña reducción en la longitud del pene. Esto puede deberse probablemente a un acortamiento de la uretra que ocurre cuando se extrae una porción de ésta junto con la próstata.

Hernia inguinal: una prostatectomía aumenta las probabilidades de que un hombre padezca de una hernia inguinal (de la ingle) en el futuro.

\section{Cáncer de próstata en cifras}

La primera radiografía sobre el cáncer en América Latina, publicada por Cáncer Epidemiology, reveló que el de próstata es el de mayor incidencia en la región. Según Globocan, en el 2012, la prevalencia de este tipo de cáncer en América Latina es de 54.2 casos cada 100 mil, con una mortalidad de 16.6 casos cada 100 mil. El estudio revela que los países de mayor desarrollo de la región, como Argentina y Brasil, presentan una alta incidencia en cáncer de próstata y mama. Mientras que países como Bolivia y Perú tienen mayores índices de cáncer de estómago y cuello uterino (Hannois, 2016).

El aumento en la cantidad de casos de cáncer de próstata se vincula con el aumento en la expectativa de vida. Al aumentar la esperanza de vida, aumenta la incidencia de este tumor. Es el tumor más frecuente en hombres mayores de 70 años y, a su vez, tiene una evolución lenta, por lo que tiene una sobrevida más alta.

El cáncer de próstata es el más común en los hombres de Ecuador y para el año 2020 el Registro Nacional de Tumores estima que habrá 3.601 nuevos pacientes con esta enfermedad. En 2018 se han reportado 3.322 nuevos casos. Quito ocupa el primer puesto con (59,3 casos por 100.000 habitantes), seguido por Cuenca (44,7), Loja $(36,6)$, Guayaquil $(27,8)$ y la zona de Manabí $(19,7)$. 


\section{Procedimientos quirúrgicos a los pacientes sometidos a una prostatectomía}

Vol. 3, núm. 4., (2019)

Gustavo Javier Palma Mieles; María Fernanda Guiracocha Orellana; Anthony James Chávez Salazar; Silvia Jimena Zambrano Salvatierra; Yahaira Fernanda Albán Poma; Jenniffer Betzabe Santistevan Holguín

Según Yépez, el de próstata ha reemplazado al gástrico en primer lugar de incidencia y mortalidad en hombres. No obstante, en relación comparativa de volumen con todos los otros tumores, representa proporcionalmente la tercera parte en la mortalidad, lo cual no sucede en otras localizaciones, donde la incidencia se parece mucho a la mortalidad, como en el caso del cáncer de pulmón, ha señalado. Casi un $40 \%$ de pacientes vienen con enfermedad avanzada, muchos son diagnosticados tempranamente y con alta probabilidad de curación, temen la disfunción sexual y la incontinencia tras el tratamiento(Coello, 2019).

\section{Conclusión.}

El cáncer de próstata es una enfermedad en la que se desarrollan células malignas (cancerosas) en los tejidos de la próstata. La próstata es una glándula del aparato reproductor masculino que queda justo debajo de la vejiga y delante del recto. Su tamaño es como el de una nuez y rodea una parte de la uretra, es posible que los pacientes con buen estado de salud y un tumor que solo está en la glándula prostática se traten con cirugía para extirpar el tumor.

La prostatectomía radical es un procedimiento quirúrgico para extirpar la próstata, el tejido circundante y las vesículas seminales. Hay dos tipos de prostatectomía radical:

- Prostatectomía retropúbica: procedimiento quirúrgico para extirpar la próstata a través de una incisión en la pared abdominal. El cirujano hace una incisión en la parte baja del abdomen, desde el ombligo.

- Prostatectomía perineal: procedimiento quirúrgico para extirpar la próstata a través de una incisión en el perineo (área entre el escroto y el ano).

Los métodos laparoscópicos conllevan realizar varias incisiones más pequeñas, se usan instrumentos quirúrgicos especiales y largos para extraer la próstata. El cirujano sostiene directamente los instrumentos, o usa un panel de control para mover con precisión los brazos robóticos que sostienen los instrumentos. La prostatectomía laparoscópica tiene sus ventajas sobre la prostatectomía radical abierta, incluyendo menos pérdida de sangre y dolor, estadías más breves en el hospital (usualmente no más de un día) y períodos de recuperación más cortos (aunque será necesario mantener el catéter en la vejiga por aproximadamente la misma cantidad de tiempo). La 


\section{Procedimientos quirúrgicos a los pacientes sometidos a una prostatectomía}

Vol. 3, núm. 4., (2019)

Gustavo Javier Palma Mieles; María Fernanda Guiracocha Orellana; Anthony James Chávez

Salazar; Silvia Jimena Zambrano Salvatierra; Yahaira Fernanda Albán Poma; Jenniffer Betzabe

Santistevan Holguín

experiencia del doctor en el uso de esta técnica obtiene similar efectividad con la prostatectomía radical laparoscópica versus la prostatectomía radical abierta.

El tipo del tumor va a influir en la decisión terapéutica de realizar una prostatectomía radical laparoscópica. Es conveniente considerar el estado de salud del paciente, la esperanza de vida (normalmente no inferior a 10 años), la supervivencia libre de enfermedad calculada con nomogramas, la calidad de vida actual, las expectativas posteriores y las complicaciones de este tratamiento, como impotencia e incontinencia urinaria de esfuerzo, entre otros, pueden influir determinantemente en la elección de este tratamiento.

El Antígeno Prostático Específico cuyos valores se obtienen con un sencillo análisis de sangre, logra la detección precoz. Antes el hombre para consultar tenía que tener algún síntoma, ahora el antígeno se indica como un control de rutina. Muchos de los factores de riesgo para el cáncer de próstata, tales como la edad, la raza, y el antecedente familiar no se pueden controlar. No existe una manera segura de prevenir el cáncer de próstata, pero tomar ciertas medidas podría reducir su riesgo. Una evaluación con el urólogo a partir de 40 años o al presentar cualquier síntoma puede ser útil. Es conveniente estar informado, en especial a los mitos sobre incontinencia e impotencia de procedimiento o técnica para combatirlo.

\section{Bibliografía.}

Sociedad Chilena de Urología. (Mayo de 2018). PROSTATECTOMIA RADICAL. Obtenido de Sociedad Chilena de Urología: https://www.urologosdechile.cl

American Cancer Society . (20 de Noviembre de 2017). Cirugía para el cáncer de próstata. Obtenido de American Cancer Society : https://www.cancer.org/es

Arroyo, C. (2007). Prostatectomía radical laparoscópica extraperitoneal con plastia inguinal. Descripción de la técnica. Revista Mexicana de Urología Volumen 67 N(2), 102 - 107 https://www.medigraphic.com/. 


\section{Procedimientos quirúrgicos a los pacientes sometidos a una prostatectomía}

Vol. 3, núm. 4., (2019)

Gustavo Javier Palma Mieles; María Fernanda Guiracocha Orellana; Anthony James Chávez Salazar; Silvia Jimena Zambrano Salvatierra; Yahaira Fernanda Albán Poma; Jenniffer Betzabe Santistevan Holguín

Castillo, O. (2006). Prostatectomía radical laparoscópica extraperitonea. Revista Chilena de Cirugía Volumen $58 N^{\circ} 1$, 40 - 44.

Coello, C. (11 de Junio de 2019). Cáncer de próstata: el de mayor incidencia y mortalidad en hombres ecuatorianos. Obtenido de Redacción Médica: https://www.redaccionmedica.ec

Eisenberg, J. (6 de Diciembre de 2016). Tratamiento del cáncer de próstata localizado. Obtenido de Effective Health Care Program: https://effectivehealthcare.ahrq.gov

El Médico Interactivo. (17 de Marzo de 2017). La laparoscopia ofrece alta precisión a la prostatectomía radical. Obtenido de El Médico Interactivo. Grupo SANED: https://dialnet.unirioja.es

Gárate, J. (2017). Prostatectomía simple laparoscópica asistida por un robot. Descripción de la técnica y resultados. Revista Chilena de Urología Volúmen $82 N^{o} 4,78$ - 85. https:www.revistachilenadeurologia.cl.

Gómez, F. (18 de Abril de 2018). Cirugía Robótica de la Próstata. Obtenido de ICUA Urología avanzada: www.icirugiarobotica.com

Hannois, A. (31 de Octubre de 2016). El cáncer de próstata, el más frecuente en la región. Obtenido de NEWSLETTERS CLARÍN: https://www.clarin.com

Instituto Nacional del Cáncer. (10 de Noviembre de 2017). Tratamiento del cáncer de próstata. Obtenido de Cigna Internacional: www.cigna.com

Reuter, M. (2008). RESECCIÓN TRANSURETRAL EN CÁNCER DE PRÓSTATA, UN PROCEDIMIENTO RADICAL. EXPERIENCIA CON 1017 CASOS. Archivo Español de Urología Volumen 61, $N^{\circ} 1,13$ - 26 http://scielo.isciii.es.

Secin, F. (2010). Anatomía quirúrgica de la prostatectomía radical: Fascias y Esfínteres Urinarios. Archivo. Español de Urología Volumen 63, $N^{\circ}$ (4), 255 - 266. https://scielo.conicyt.cl. 
Procedimientos quirúrgicos a los pacientes sometidos a una prostatectomía

Vol. 3, núm. 4., (2019)

Gustavo Javier Palma Mieles; María Fernanda Guiracocha Orellana; Anthony James Chávez Salazar; Silvia Jimena Zambrano Salvatierra; Yahaira Fernanda Albán Poma; Jenniffer Betzabe

Santistevan Holguín

$$
\text { (c) } \frac{1}{\mathrm{BY} \text { NC } \mathrm{SA}}
$$

RECONOCIMIENTO-NOCOMERCIAL-COMPARTIRIGUAL

CC BY-NC-SA

ESTA LICENCIA PERMITE A OTROS ENTREMEZCLAR, AJUSTAR Y CONSTRUIR A PARTIR DE SU OBRA CON FINES NO COMERCIALES, SIEMPRE Y CUANDO LE RECONOZCAN LA AUTORÍA Y SUS NUEVAS CREACIONES ESTÉN BAJO UNA LICENCIA CON LOS MISMOS TÉRMINOS. 